\title{
Lubens enigki sp. n. (Digenea : Dicrocoeliidae) from the Philippine Rail, Rallus rallus pbilippensis (L.)
}

\author{
by L. Eduardo SALCEDO $\left({ }^{*}\right)$ \\ Department of Parasitology, Institute of Veterinary Medicine \\ Araneta University Foundation, Malabon, Rizal, Philippines
}

Summary.

Lubens enigki sp. $\mathrm{n}$. is described and illustrated from the gall bladder of Rallus rallus philippensis (L.) in the Philippines. It is compared with all the known species of the genus Lubens. This is the first record of a species of the genus to be reported from the Philippines.

\section{Résumé.}

Lubens enigki sp. n. (Digenea, Dicrocoeliidae) du râle philippin Rallus rallus philippensis (L.).

Lubens enigki sp. n. est décrit et illustré de la vésicule biliaire de Rallus rallus philippensis (L.) aux Philippines. On le compare à toutes les espèces connues du genre Lubens. C'est la première fois que l'on a signalé aux Philippines une espèce de ce genre.

The present paper deals with the description of a heretofore undescribed species of the genus Lubens (Travassos, 1919) Strom, 1940 from the gall bladder of the philippine rail, Rallus rallus philippensis (L.). This is a part of the author's collection in the course of examination of philippine wild birds for parasites.

(*) Present Address: Institut für Parasitologie der Tierärztlichen Hochschule, 3 HannoverKirchrode, Bünteweg 17, Bundesrepublik Deutschland. 
Worms were washed in normal saline solution, fixed in Bouin's fluid, stained in borax carmine and mounted mens were also observed prior to fixation. Drawing and measurements were done with the aid of camera lucida and ocular micrometer. All measurements are in millimeters unless stated otherwise.

\section{Lubens enigki}

Description (based on two mature specimens, one of which is partly damaged) : Body oval, aspinose, extremities rounded, 6.25-6.50 long by 3.60-3.82 wide, maximum width at equator. Suckers close to each other, about 0,373 apart ; oral sucker subterminal, $0.63-0.65$ by $0.85-0.86$; acetabulum well developed, larger than oral sucker

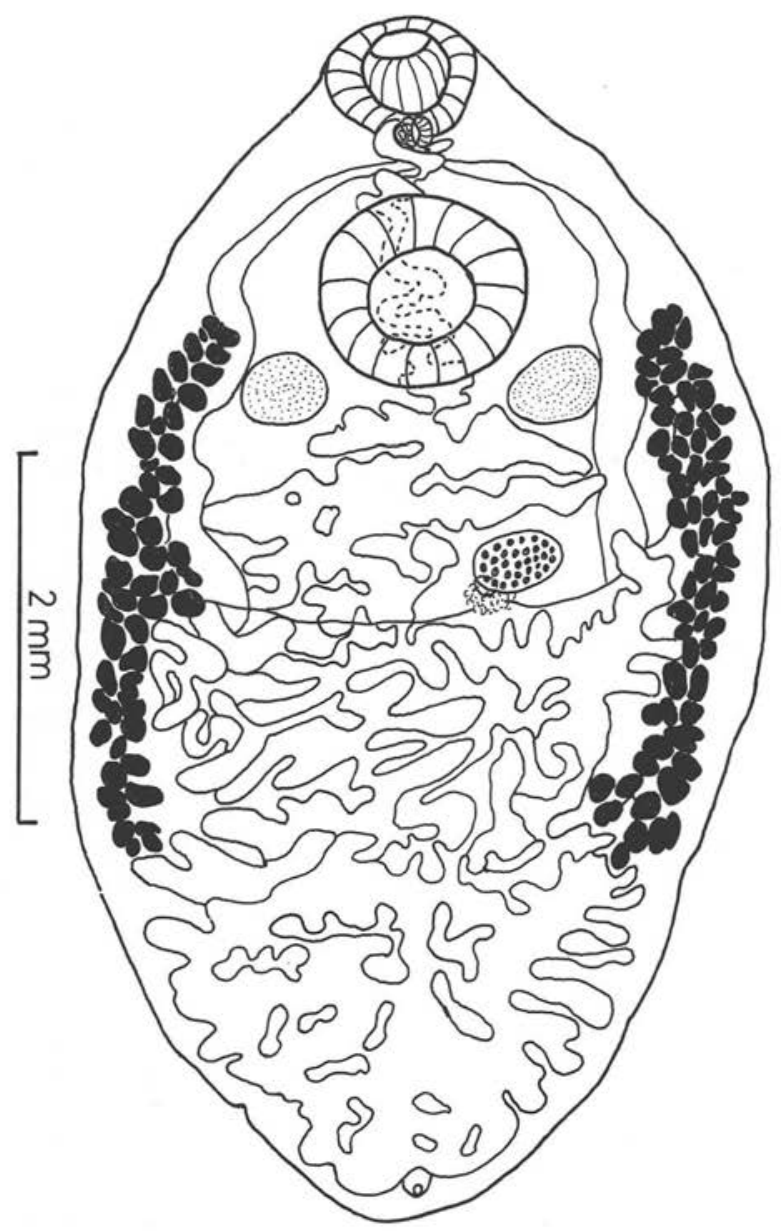

Fıg. 1. - Lubens enigki sp. n., ventral view. 
round or nearly so, $1.04-1.75$ by 1.15 ; sucker length ratio $1: 1.61$, width ratio $1: 1.36$. Prepharynx absent; pharynx overlapping oral sucker, slightly wider than long, 0.18 by 0.21 ; esophagus short ; cecal bifurcation midway between suckers; ceca sinuous terminating short of posterior extremity (fig. 1).

Testes two, symmetrical, lying in the same horizontal plane on each lateral side of the posterior level of the acetabulum but not touching it, round to slightly oval, about $0.97-1.20$ wide apart separated by ascending coils of uterus; right testis $0.43-0.48$ by $0.48-0.51$; left testis $0.43-0.52$ by 0.53 ; cirrus pouch greatly reduced, confined only within the pharyngeal zone; genital pore opening at anterior level of pharynx.

Ovary sinistral, transversely elongate, smooth margin, 0.486 by 0.324 , about 0.9 postacetabular or 0.5 post left testicular separated by uterine loops from the latter. Mehlis' gland well developed, partly overlapping ovary, dorsal and postero-dextral to it; seminal receptacle small, dorsal to and overlapped by ovary and Mehlis' gland; Laurer's canal present. Vitellaria arranged in grape-like clusters in each extracecal field, partly invading ceca. Vitellaria commence at posterior level of acetabulum terminating about 1.206 postovarian, postvitellarian space 2.20 long. Uterus highly convoluted, filled with eggs, extends posteriorly occupying the entire hind region of the body and obscuring ceca and partly overlapping vitellaria. Eggs numerous 27.2-35.2 by $17.6-19.2$ microns.

Excretory bladder is tubular; excretory pore subterminal.

Host : Rallus rallus philippensis (L.).

LOCATION: Gall bladder.

Locality : Palawan Island, Philippines.

Holotype will be kept in the helminthological collection of the Institute of Parasitology of the School of Veterinary Medicine Hannover.

\section{Discussion}

Skrjabin et Evranova (1952) placed seven species under the genus Lubens (Travassos, 1919) Strom, 1940. Yamaguti (1971) listed two additional species but suppressed L. robustum (Travassos, 1919) Skrjabin et Evranova, 1952 and synonimized it to the type species L. lubens (Braun, 1901) Strom, 1940. North, Central and South America are so far the only localities from which species of this genus have been previously reported.

The philippine form differs from all known species of the genus in the suckers closer to each other, ventral larger than oral sucker thus greater sucker ratio and in host and locality. The new species differs further from L. intermedium (Travassos, 1919) Skrjabin et Evranova, 1952 and L. centroamericanum Brenes, Arroyo et Munoz, 1966 in the anterior extent of vitellaria and the position of the testes, both of which are at the hind level of the acetabulum rather than postacetabular, the sinistral position of the ovary and the ceca does not reach posterior end of the body. L. intermedium differs also in its smaller, asymmetrical testes, in shape and size of ovary and in 
larger eggs; L. centroamericanum in addition differs in the position of the genital pore and the cirrus pouch.

The following species are distinguishable further from L. enigki; L. lubens in its more elongate body, ovary larger than and closer to testis and vitellaria occupy only anterior half of the body; L. cuyabai (Travassos, 1922) Skrjabin et Evranova, 1952 in the oral larger than the ventral sucker, smaller pharynx, larger esophagus, smaller testes, ceca reach posterior end of the body and greater width of egg; L. phelpsi Heyneman, Brenes et Diaz-Ungria, 1960 in its larger size, relative position of testes in relation to acetabulum and in egg size; L. polymorphum (Travassos, 1919) Skrjabin et Evranova, 1952 in its smaller pharynx, oral sucker as well as body size, testes which are unequal in shape, size and position, equatorial position of ovary, unequal vitellaria and in egg size; L. robustum (Travassos, 1919) Skrjabin et Evranova, 1952 in its larger body size, smaller testes which are postacetabular, in shape of ovary and larger egg.

The most recent work on Dicrocoeliid trematodes from philippines birds is that of Fischthal et Kuntz (1973). Like previous reports on parasites of philippine birds, no findings have been given on any species of the genus Lubens. This is therefore the first record of a species of the genus Lubens to be reported from the Philippines and thus expanding the geographical distribution of the genus outside the Americas.

\section{ACKNOWLEDGEMENTS}

The new species is named in honor of Pr. Dr. Dr. h.c. Karl Enigk, Director of the Institute of Parasitology, School and Veterinary Medicine Hannover in recognition of his contributions to Veterinary Parasitology and whose helps, encouragement and for the use of the Institute's Library, the writer is greatly indebted. I would like also to acknowledge the financial support of the German Academic Exchange Service (DAAD) in the form of study grant.

\section{Bibliography}

Brenes (R. R.), Arroyo (G.) et Munoz (G.), 1966. - Helminthos de la Republica de Costa Rica XXI. Algunos trematodos de aves silvestres 2. Rev. Biol. trop., 14, 123-132.

Fischthal (J. H.) et Kuntz (R. E.), 1973. - Brachylaimid and Dicrocoeliid trematodes of birds from Palawan Island, Philippines. Proc. Helm. Soc. Wash., 40, 11-22.

Heyneman (D.), Brenes (R. R.) et Diaz-Ungria (C.), 1960. - Trematodos de Venezuela. II. Algunos trematodos de peces, reptiles y aves con descripcion de una nueva especies del genero Lubens. Mém. Soc. Cien. nat., 20, 138-149.

SkrJabin (K. I.) et Evranova (V. G.), 1952. - Semeistvo Dicrocoeliidae Odhner, 1911. In: Trematody zivotnych celoveka. Osnovy trematodologii, 7, 33-604.

Travassos (L.), 1944. - Revisao da familia Dicrocoeliidae, Odhner, 1911. Monogr. Inst. Oswaldo Cruz, 2, 357 p.

Yamaguti (S.), 1971. - Synopsis of Digenetic Trematodes of Vertebrates, vol. 1. Keigaku Publishing Co., Tokyo, 1074 p. 